\title{
IS THERE ANY DIFFERENCE IN EFFICACY OF ORAL SILDENAFIL THERAPY IN PRIMARY VS SECONDARY PULMONARY ARTERIAL HYPERTENSION?
}

\author{
"Ghosh Abishek ${ }^{1}$, Biswas Rajat Kanti², Das Asoke Kumar', Pal Ananya ${ }^{3}$, Ghosh Souvik ${ }^{4}$, Ghosh Balaram ${ }^{4}$ \\ ${ }^{1}$ Department of Pharmacology, R.G. Kar Medical College, Kolkata \\ ${ }^{2}$ Department of Pharmacology, Maldah Medical College, WB \\ ${ }^{3}$ Department of Pathology, N.R.S. medical College, Kolkata \\ ${ }^{4}$ Department of Pharmacology, Medinapore Medical College, WB \\ *Corresponding author: Dr. Abhishek Ghosh, Email id: drghosh.new@gmail.com
}

Received 26 Nov 2012; Review Completed 09 Jan 2013; Accepted 14 Jan 2013, Available online 15 Jan 2013

\begin{abstract}
Objective: Oral sildenafil, a phosphodiesterase 5 inhibitor,is now accepted mode of therapy for symptomatic Pulmonary arterial hypertension(PAH).As the pathobiologic mechanisms are different in primary and secondary PAH, we undertook this study to find out any significant difference in efficacy of oral sildenafil therapy in primary versus secondary PAH.

Methods: It was an unicentric parallel group longitudinal study. After selection and baseline investigations,all the patients of primary and secondary PAH were given sildenafil in fixed doses (50 $\mathrm{mg}$ thrice daily).

Study parameters: 1 . Distance covered in 6 minute walk test (6MWT), 2.Pulmonary arterial pressure (PAP) by trans-thoracic Doppler echocardiography, 3.quality of life (QOL) score assessed by Minnesota living with heart disease questionnaire. At the end of 6 weeks, 6 MWT, PAP, QOL were compared to the baseline value.

Results: 42 subjects completed the study.20 subjects had primary PAH and 22 had secondary PAH. Sildenafil therapy was effective in both groups in reducing PAP, increase in distance covered in 6 minute walk and reducing QOL score. Reduction of PAP is significantly more in primary PAH than secondary PAH but no such difference was found in 6 MWT and QOL score.

Conclusion: Though lowering of pulmonary arterial pressure in primary PAH is significantly lower than secondary PAH, this is not translated in better symptomatic relief.

Key words: primary pulmonary hypertension, secondary pulmonary hypertension, sildenafil, pulmonary arterial pressure, 6 minute walk test.
\end{abstract}

\section{INTRODUCTION}

Pulmonary arterial hypertension (PAH) is a condition characterized by a progressive elevation of mean pulmonary arterial pressure to more than $25 \mathrm{~mm}$ of $\mathrm{Hg}$ at rest or to more than $30 \mathrm{~mm}$ of $\mathrm{Hg}$ with exercise. ${ }^{1}$ Patients present with exertional dyspnoea, chest pain, syncope/near syncope, fatigue and ultimately manifestation of right heart failure over months to years. ${ }^{2,3}$

$\mathrm{PAH}$ is of two major types. First is primary PAH where there is no identifiable cause and includes idiopathic PAH (IPAH) and familial PAH (FPAH). Another is PAH secondary to left heart disease (valvular heart diseases, left atrial and ventricular diseases), diseases of lung which causing hypoxemia [Chronic obstructive Pulmonary Disease (COPD), Interstitial lung disease, sleep disorders, high altitude etc], connective tissue disorders (systemic sclerosis), chronic thromboembolic disease and generalized serious infections, e.g. HIV. ${ }^{4}$

Pathobiology of PAH is multifactorial. ${ }^{5,6}$ Increased thromboxane $A_{2}$, endothelin 1 and decreased Nitric oxide, prostacyclin $\left(\mathrm{PGI}_{2}\right)$ cause vasoconstriction of small arteries and arterioles due to chronic hypoxemia and remodeling of vascular wall due to proliferation of smooth muscle cells and endothelial cells ( which become apoptosis resistant). Therapies targeted against these 2 changes provide the basis for current pharmacotherapy of $\mathrm{PAH}$.
Pharmacological management of PAH is generally unsatisfactory. Vasodilators are mainstay of therapy but are handicapped with a serious disadvantage. They also lower systemic blood pressure thus leading to lower pulmonary perfusion compounding hypoxemia. Various agents used also have adverse effects of their own. Currently approved therapies 4,7,8 include prostacyclin ( $\mathrm{PGI}_{2}$ : Epoprostenol), which needs to be given by continuous infusion due to its short half life or stable $\mathrm{PGI}_{2}$ analogues like iloprost (given by inhalation 6-9 times per day) or teprostinil ( given by continuous subcutaneous. infusion). Oral Bosentan (endothlin receptor antagonist), though effective, causes serious hepatotoxicity and teratogenicity. ${ }^{8}$ All these drugs are very expensive too.

The need for a cheap, oral, effective vasodilator of pulmonary vasculature was met by Phosphodiesterase type $5\left(\mathrm{PDE}_{5}\right)$ inhibitor, sildenafil, ${ }^{9.10}$ which when used in a dose of $50 \mathrm{mg}$ thrice daily (much lower than dose used for erectile dysfunction) reduces pulmonary resistance and improved exercise tolerance. Low dose is effective as pulmonary vasculature is rich in $\mathrm{PDE}_{5}$. Benefit of sildenafil was also demonstrated in suitable animal models of PAH ${ }^{11}$ as well as patients of idiopathic $\mathrm{PAH}^{12}$ and secondary PAH ${ }^{[13]}$. Oral sildenafil in low dose is now accepted mode of therapy for symptomatic PAH. 
We were intrigued by the fact that temporal evolutions of pathobiologic mechanisms of PAH are different in primary and secondary PAH. Whether this translates into any difference in efficacy of oral sildenafil therapy between two groups of PAH is an open question. Therefore we undertook this study to evaluate and find out any significant difference in efficacy of oral sildenafil therapy in primary versus secondary PAH.

\section{MATERIALS AND METHODS}

The protocol along with the informed consent form was approved by institutional ethics committee. Informed written consent was taken from all patients before enrolment.

It was a unicentric parallel group longitudinal study. All the patients who attended the OPD or admitted in indoor who fulfilled all the inclusion criteria and not excluded by any one/more of the exclusion criteria (table 1) were included in the study.

Total 42 patients were included in study, 20 with primary and 22 with secondary PAH. Study was continued for eight months.

\section{Study parameters:}

Primary: Distance covered in 6 minute walk test. (6MWT)

\section{Secondary:}

1. Pulmonary arterial pressure (PAP) by transthoracic Doppler echocardiography (TR jet method).

2. Quality of life (QOL) score assessed by predesigned Minnesota living with heart disease questionnaire.

Baseline investigations were done which included 12 lead electrocardiography, chest x ray, trans-thoracic Doppler echocardiography, walking/exercise capacity measured by 6 minute walk test, complete hemogram and blood tests for urea, creatinine, total cholesterol, fasting sugar, bilirubin, ALT,AST, Alkaline phosphatase. Quality of life was assessed from standard criteria.

After selection and baseline investigations, all the patients of primary and secondary PAH were given sildenafil in fixed doses (50 mg thrice daily). Before dispensing any drug, drug tolerability test was carried out. Patients were given $25 \mathrm{mg}$ sildenafil initially and repeated after 6 hours under observation. If there was no hypotension, then they were selected to give $50 \mathrm{mg}$ thrice daily and included in the study.

The therapy was given for 6 weeks and patients were followed up every 2 weeks. At each follow up visits the drug was dispensed and all baseline investigations and tests were repeated.

At the end of 6 weeks, 6 MWT, PAP by Doppler echocardiography, QOL assessment was done again and compared to the baseline value.

The relevant data were collected in the form of mean \pm standard deviation. Changes in efficacy parameters at baseline and at the end of study were analysed using paired $t$ test within same group and unpaired $t$ test between the groups. The level of significance was taken as $\mathrm{p}<0.05$.

\section{RESULTS}

Among the 42 subjects who completed the study and received end of trial certification, 20 subjects had primary PAH and 22 subjects had secondary PAH. Among 22 secondary PAH patients, 9 cases were due to COPD, 4 were due to bronchial asthma, 6 patients had different valvular and congenital heart diseases like atrial septal defect, 2 cases were due to interstitial lung disease and 1 case was due to systemic sclerosis.

Among 42 subjects, 28 patients were male and 14 were female. Average age of primary PAH was 18.25 years and of secondary PAH was 32.80 years.

Effect on distance covered in 6 min walk test (6 MWT): The study showed significant increase in distance covered in 6 minutes on horizontal surface when the patients were treated with sildenafil for 6 weeks. (table 2)

So increase in distance covered was extremely significant when compared with baseline value in both primary and secondary $\mathrm{PAH}$, as measured by paired $\mathrm{t}$ test. But the increase in distance covered due to sildenafil therapy did not differ significantly between primary $\mathrm{PAH}$ and secondary PAH group ( $\mathrm{p}$ value $=0.5881$ ), when measured by unpaired t test.

Effect on pulmonary arterial pressure (PAP): Sildenafil caused very significant reduction in pulmonary arterial pressure after 6 weeks therapy in both primary and secondary PAH when compared with the baseline values, when measured by paired t test. (table 3 )

The reduction in pulmonary arterial pressure was significantly more in patients with primary $\mathrm{PAH}$ than patients with secondary PAH $(\mathrm{p}=0.0001)$, as measured by unpaired t test.

Effect on quality of life scores: Quality of life (QOL) score was assessed out of total score 105 in Minnesota living with heart disease questionnaire. Sildenafil therapy showed very significant improvement in functional capacity of the patients by significant lowering the QOL score in both primary and secondary PAH after 6 weeks of therapy.(table 4)

But the reduction in QOL score due to sildenafil therapy for 6 weeks did not differ significantly between primary PAH and secondary PAH group ( $\mathrm{p}$ value $=0.3361$ ), when measured by unpaired test.

\section{DISCUSSION}

The present study shows that sildenafil citrate in $50 \mathrm{mg}$ t.i.d. dosage is very effective in reducing Pulmonary arterial pressure (PAP) in patients of both primary and secondary PAH which is in concordance with numerous studies done previously. $7,13,14,15,16 \mathrm{We}$ found sildenafil causes significantly more reduction of PAP in primary PAH than secondary PAH. Though changes in PAP as measured by Doppler echocardiography may not be accurate in absolute terms still the difference remains significant as procedural errors will have equal effect on both arms of the study and therefore without impact on end result. While we thought that the significant difference in PAP reduction between the two groups would have an impact on exercise tolerance and quality of life parameters in the patients, we found that it was not so. 
We found that sildenafil was very effective in improving exercise tolerance in patients of PAH regardless of primary or secondary etiology as judged by our findings in 6 minute walk test. (mean distance covered increased from $307.4 \mathrm{~m}$ to $419.8 \mathrm{~m}$ in primary PAH and from $326.36 \mathrm{~m}$ to $426.45 \mathrm{~m}$ in secondary PAH.) This is in agreement with SUPER study by Galie N, Ghofrani HA, Torbicki A et al in $2005^{13}$ and other studies too ${ }^{12,14}$

The functional capacity of the patients was also significantly improved by 6 weeks sildenafil therapy as detected by lowering of quality of life score from baseline.

Therefore after 6 weeks of sildenafil therapy, the improvement in exercise tolerance, functional capacity and clinical status, which in all probability was due to increase in cardiac output and a decrease in pulmonary vascular resistance, was not different regardless of etiology of PAH, i.e., primary or secondary causes.

Limitations of the study are also worth a mention. Being parallel group study, subject matching at baseline gains added importance. While the matching as regards the degree of PAH was satisfactory but age matching was not possible as the average age of presentation of primary
PAH was significantly less than that of secondary PAH (18.25 years and 32.80 years respectively) for obvious reason.

In our study there was a preponderance of male patients (28 male and 14 female) but sexes were more or less evenly distributed between two groups. Other limitations were short duration of study, relatively small sample size and use of non-invasive efficacy parameters. However, submaximal exercise testing ( 6 minute walk test) is a popular method of evaluating efficacy of drug therapy in symptomatic PAH and independently related to mortality in primary PAH as evident from previous studies on this topic.

\section{CONCLUSION:}

Though lowering of pulmonary arterial pressure in primary PAH as measured by trans-thoracic echocardiography is significantly lower than secondary PAH, this is not translated in better symptomatic relief, as guided by 6 minute walk test and quality of life score. So benefit acquired by sildenafil is almost equivalent in both primary and secondary $\mathrm{PAH}$.

\section{Table 1: Subject selection criteria}

\begin{tabular}{|l|l|}
\hline Inclusion criteria & Exclusion criteria \\
\hline Patients with PAH of both primary & Patients with renal or hepatic dysfunction. \\
and secondary cause. & Patients aged less than 12 years or more than 75 years. \\
PAP is more than $30 \mathrm{~mm}$ of Hg. & Weight less than $30 \mathrm{~kg}$ \\
Patients with NYHA class II \& III & Patients showing severe hypotension on test dose with other contraindications to \\
and are able to walk & sildenafil. \\
Adult age group between 12 to 75 & Patients with NYHA class IV symptoms, coronary heart disease, severe \\
years of age. & hypertension. \\
& Patients taking vasodilator, especially nitrates, calcium channel blockers. \\
& Pregnant/lactating women \\
& PAH due to HIV/any severe infections. \\
\hline
\end{tabular}

Table 2: Effect of sildenafil on 6 minute walk test

\begin{tabular}{|c|c|c|c|}
\hline 6 min walk test & $\begin{array}{c}\text { Mean } \pm \text { S.D. before } \\
\text { sildenafil (In metres) }\end{array}$ & $\begin{array}{c}\text { Mean } \pm \text { S.D. after sildenafil } \\
\text { ( In metres) }\end{array}$ & P value \\
\hline Primary PAH & $307.4 \pm 40.13$ & $419.8 \pm 59.66$ & $<0.0001$ \\
\hline Secondary PAH & $326.36 \pm 62.45$ & $426.45 \pm 69.02$ & 0.0002 \\
\hline
\end{tabular}

Table 3: Effect of sildenafil on Pulmonary arterial pressure

\begin{tabular}{|c|c|c|c|}
\hline $\begin{array}{c}\text { Pulmonary arterial } \\
\text { pressure }\end{array}$ & $\begin{array}{c}\text { Mean } \pm \text { S.D. before } \\
\text { sildenafil }(\text { in } \mathrm{mm} \text { of } \mathrm{Hg})\end{array}$ & $\begin{array}{c}\text { Mean } \pm \text { S.D. after } \\
\text { sildenafil }(\text { in mm of Hg) }\end{array}$ & P value \\
\hline Primary PAH & $71.8 \pm 11.42$ & $37.3 \pm 6.04$ & $<0.0001$ \\
\hline Secondary PAH & $65.09 \pm 11.46$ & $43.18 \pm 11.14$ & $<0.0001$ \\
\hline
\end{tabular}

Table 4: Effect of sildenafil on quality of life

\begin{tabular}{|c|c|c|c|}
\hline QOL score & $\begin{array}{c}\text { Mean } \pm \text { S.D. before } \\
\text { sildenafil }\end{array}$ & $\begin{array}{c}\text { Mean } \pm \text { S.D. after } \\
\text { sildenafil }\end{array}$ & P value \\
\hline Primary PAH & $41 \pm 7.75$ & $29.8 \pm 7.19$ & 0.0107 \\
\hline Secondary PAH & $38.09 \pm 10.63$ & $27.82 \pm 6.94$ & 0.0005 \\
\hline
\end{tabular}




\section{REFERENCES}

1. Gaine SP, Rubin LJ. Primary pulmonary hypertension, Lancet; 1998, 352: 719-725

2. Chin KM, Rubin LJ. Pulmonary arterial hypertension, J Am Coll Cardiol.;2008, 51:1527-1538

3. Rich S, Pulmonary hypetnsion; Fauci AS, Braunwald E, Kasper DL, Hauser SL, Longo DL, Jameson JL, Loscalzo J. Harrison's principles of internal medicine $17^{\text {th }}$ ed. 2008, Volume 2, New York Mcgraw Hills.

4. Rich S, McLaughlin VV. Pulmonary hypertension; Zipes DP, Libby P, Borow RO, Braunwald E, Braunwald's Heart Disease $7^{\text {th }}$ ed. 2007, Elsevier, Saunders.

5. Humbert M, Morrell NW, Archer SL, et al. Cellular and molecular pathobiology of pulmonary arterial hypertension study. Am J Med; 1951, 11:686

6. Farber H, Loscalzo J. Pulmonary arterial hypertension, $N$ Eng J Med.; 2004, 351:1655-1665

7. Galie N, Seeger W, Naijie R, Simonneau G, Rubin LJ. Comparative analysis of clinical trials and evidence based algorithm in pulmonary arterial hypertension, J Am Coll Cardiol.; 2004, 43:suppl12: 81s-88s

8. Humbert M, Sitbon O, Simonneau G et al. Medical therapy for pulmonary arterial hypertension. N Eng J Med.; 2004, 351: 14251436

9. Corbin JD, Francis SH. Cyclic GMP phosphodiesterase 5: target of sildenafil, J Biol Chem.; 1999, 274:13729-13732
10. Tantini B, Manes A, Fiumana E et al. antiproliferative effect of sildenafil on human pulmonary arterial smooth muscle cells, Basic Res Cardiol.;2005, 100:131-138

11. Cohen AH, Hanson K, Morris K et al. Inhibition of cyclic 3'-5'guanosine monophosphate specific phosphodiesterase selectively vasodilates the pulmonary circulation in chronically hypoxic rats, J Clin Invest.; 1996, 97:172-179

12. Sastry BKS, Narasimhan C, Reddy NK, Raju BS. Clinical efficacy of sildenafil in primary pulmonary hypertension, $J$ Am Coll Cardiol.; 2004, 43:1149-1153

13. Galie N, Ghofrani HA, Torbicki A et al for the sildenafil use in pulmonary arterial hypertension (SUPER) study group. Sildenafil citrate therapy for pulmonary arterial hypertension, $N$ Eng J Med.; 2004, 353:2148-2157

14. Garg N, Sharma MK, Sinha N. Role of oral sildenafil in severe pulmonary arterial hypertension: clinical efficacy and dose response relationship, Int J Cardiol.;2007, 120:306-313

15. Sing TP, Rohit MK, Grover A, Malhotra S, Vijayvergiya R . A randomized placebo-controlled, double-blind, crossover study to evaluate the efficacy of oral sildenafil therapy in in severe pulmonary arterial hypertension, Am Heart J.; 2006, 151:851.e1$851 . e 5$

16. Bharani A, Mathew V, Sahu A, Lunia B. The efficacy and tolerability of sildenafil in patients with moderate to severe pulmonary hypaertension, Indian Heart J.;2003, 55(1):55-59 